\title{
Mobile Phones as a Challenge for m-Learning: Examples for Mobile Interactive Learning Objects (MILOs)
}

\author{
Andreas Holzinger ${ }^{1}$, Alexander Nischelwitzer ${ }^{2}$, Matthias Meisenberger ${ }^{2}$ \\ ${ }^{1}$ Institute for Medical Informatics, Statistics \& Documentation, Graz Medical University \\ ${ }^{2}$ School of Information Management, University of Applied Sciences FH JOANNEUM \\ andreas.holzinger@uni-graz.at \\ alexander.nischelwitzer@fh-joanneum.at \\ matthias@mlearn.net
}

\begin{abstract}
The widespread use of mobile phones (in Europe often called "Handies") enables a long awaited dream: Learning at any place, at any time. This "not being tied to particular locations" is for example especially interesting in the area of medicine i.e. for vocational training of medical staff and students. As the amount of medical information continues to grow, timely access to information is critical to medical personnel. However, such applications can not be the 1:1 transformation of standard computerized learning material; special design issues must be considered. In this paper we present a practical approach to $\mathrm{m}$ Learning and call it "Mobile Interactive Learning Objects (MILOs) which are used within a Mobile Learning Engine (MLE) that runs on mobile phones. MILOs can offer manifold possibilities for new kinds of communication and explorative learning.
\end{abstract}

\section{Introduction}

It is acknowledged that Mobile Computing (MoCo) is one of the most challenging future fields in computer science [1] especially at European Level [2]. Mobile Computing encompasses any technology that enables people to access information and supports them in daily workflows independent of location [3].

Actually, it is remarkable that many of the Mobile Computing research results and breakthroughs come from the Human-Computer Interaction (HCI) field [4]. However, there is still room for a great deal of progress in this extremely successful and worthwhile area of endeavor. The phenomenal growth of Mobile Computing [5], whereby a parallel growth of user sophistication has failed to take place, will increase the need for future research in fully adaptive and sensitive interfaces, aware of the requirements and proficiency of users.

\section{Example Domain: Medicine/Health Care}

Medical doctors and nurses work in an environment which requires high mobility [6], [7], [8], Within their daily routine their sphere of activity alters frequently between wards, outpatient clinics, diagnostic and therapeutic departments and operating theatres. Although access to stationary clinical workstations is provided in the hospital, their locations do not always coincide with the user's current workplace. In order to fulfil a high health service standard the medical staff has an extensive demand for information at a number of locations - which actually only mobile computers can supply [9], [10]. People always need clear added values when using technology. Within this domain, one benefit can be providing the necessary mobility amongst students to support, for example, bed side teaching or problem based learning.

\section{From e-Learning to m-Learning}

Complete independence of both location and time is often emphasized as the main advantage of e-Learning [11]. However, in traditional e-Learning the minimum hardware requirement is still a Personal Computer (PC), consequently an absolute independence in location is not provided. These independencies are still not fulfilled with the use of a notebook, because a real independency in time and location means learning wherever and whenever a person wants to have access to learning material. Mobile learning (m-Learning) is the next generation of e-Learning and is based on mobile devices [12]. One advantage is the high availability of such devices: the market penetration of mobile phones in Austria is currently at a level of $81 \%$ and the numbers are still increasing [13]. It can be emphasized that the majority of the population have a mobile at hand most of the time. Thus, m-Learning will be an important instrument for lifelong learning. 


\section{Constructivistic m-Learning Scenarios}

The available mobile technology can enhance the shift from pure instructor centered classroom teaching to constructivist learner centered educational settings away from the classroom; for example in outside learning environments -medical education is a good example.

It should be taken into consideration that a mobile phone is still a phone, subsequently the didactical possibilities include the ability to provide communication (both speech and text) to and from the teacher and amongst peers. This is essential to provide feedback, which can be seen as a core element in any constructivistic scenario.

Consequently the proper use of such devices offers enormous possibilities for the application in a constructivist learning setting.

However, didactical and pedagogical approaches to achieve such constructivist settings include explorative learning, scaffolding and situated learning. Fundamental to all of these approaches is problem solving.

\subsection{Problem Solving}

Active problem solving is central for constructivist learning. Within cognitive science, problem solving is synonymous with learning and viewed as the manipulation of problematic situations, comprising the appraisal of the problem, creation of a problem space, the selection of goals, and the deployment and monitoring of cognitive structures to reach those goals [14], [15], [16].

Problem Based Learning (PBL) originates from education in medicine [17] and is still the preferred educational method in the medical domain. In a typical PBL-setting, the work by the students (and faculty) is organized in projects, whereby the project aims at working towards solving a particular problem. One aspect of PBL is that the emphasis is on meaning and not facts; consequently having a mobile device at hand with access to relevant information (e.g. facts) required in a particular context is extremely helpful in this setting.

\subsection{Exploratory Learning}

In exploratory learning, the end-users (learners) investigate a system on their own, often in pursuit of a goal. Exploratory learning [18] is a constructivist instructional approach, wherein the learners are encouraged to explore and to experiment on their own often in pursuit of a goal [19]. This approach is in opposition to working through precisely sequenced learning material in behaviorist style [20], [21].

Exploratory learning is not unguided browsing; it is considered most appropriate for training problemsolving skills.

Due to the fact that mobile phones are excellent communication devices, the opportunity for codiscovery learning is also at hand: Learners can cooperate in a manner which supports co-operative problem solving. This is, on the one hand, motivating for the learners, on the other hand a means of expanding their learning resources. The learners receive additional sources of scaffolding since they gain by the competencies of the other group members. It is generally known that sometimes members of the peer group are better able to explain material to colleagues than experts.

\subsection{Situated Learning}

The principle of situated learning is a combination of cognitivistic and constructivistic approaches. The specific learning situation plays a central role during the knowledge construction process. During a situated learning setting, the mental representation of a concept occurs not in an abstract or isolated form but in connection with the social and material context of a specific learning situation [22], [23].

Although the term situation is not exactly defined, situation encompasses aspects of the physical, social and cultural environment including the communication with peers during the learning process. Recent research on human learning challenges the separation of what is learned from how and where it is learned.

The circumstances in which knowledge is developed and deployed are not separable from or ancillary to learning. In the approach of situated learning the circumstances are an integral part of what is learned, consequently all learning is more or less situated [22]. 


\section{The MLE enables m-Learning}

The Mobile Learning Engine (MLE) is a multimediabased application for mobile phones and is available free of charge via: www.mlearn.net

The MLE has been developed by using the Java 2 Micro Edition (J2ME). Its platform independency enables the handling of:

- Different operating systems (Symbian OS, Microsoft MS Pocket PC, Palm OS, etc.);

- A variety of different screen resolutions;

- Different input possibilities (keypad, keyboard or pointer device);

To realize a platform-independent application, which can be used on a variety of different operating systems of mobile phones, a standardized development environment is necessary, such as the Java 2 Micro Edition (J2ME). Almost every mobile phone to-date is Java-enabled, this means it is capable of executing a J2ME application. J2ME is platform-independent and makes the creation of mobile, internet-based applications possible. With the use of additional libraries multimedia-based applications can be created. The implementations of these additional libraries vary from producer to producer but the basic rule is: the newer the Smartphone, the more J2ME libraries are supported. Nevertheless the core application should work without these additional libraries but if they are available the additional features should be used.

A core ability of the MLE is the presentation of learning objects. The following features are realized (some are shown in figures 6 and 7):

- Formatted continuous text;

- Integration of images within text;

- Hyperlinks and elements with specific actions;

- Audio and Video bars for playback (also streaming from a server is possible); including:

- Interactive questions and intelligent help,

- Checkbox questions (single choice, multiple choice);

- Order questions;

- Inserting characters questions (text match and numbers match);

- Graphical order questions;

- Graphical marking questions - marking of certain regions (hot spots) within a picture.

\section{Mobile Interactive Learning Objects}

Mobile Interactive Learning Objects (MILOs) for mLearning can generally be structured the same way as Learning Objects for e-Learning [24]. The obvious differences remain in the presentation and the amount of information offered. Due to the limitation of the screen size, very little continuous text should be used. Instead, different kinds of media should be applied. For example: figures and pictures, videos or audio and most important - the possibility of the output of spoken text. Nevertheless, a MILO shouldn't contain as much information as a traditional learning object (LO). Therefore, it is advisable to split up a topic into separate MILOs, which are related but should also be independent of each other.

Another aspect that should be considered within the creation of a MILO is the method of use. If end-users work through the learning material, it can be assumed that they take a certain amount of time and concentrate on the subject. Within m-Learning there is a totally different scenario because it must be expected that it will primarily be used during idle periods. However, these idle periods can end abruptly [25].

For example: a medical student, waiting for a bus, can decide to use this spare time for learning on a mobile phone. On the arrival of the bus he must discontinue learning. After he is seated, he wishes to continue learning until arrival at the training hospital.

The MILO should be structured to allow the user to stop learning abruptly and to continue learning after an indefinite period of time. This special kind of use requires that the structure of the learning content is in small and homogeneous information chunks [26], [27], [28]. These information chunks should fit one screen. If the users stop abruptly it should be possible to continue learning just by activating the last information chunk.

In contrast to passive, receptive, traditional learning, MILOs should be designed for explorative learning. Explorative learning or discovery learning [18], [29] is a method of learning without a rigid path. Consequently users can explore or discover the available learning content independently [30].

A representative example for explorative learning is a hypermedia system (networked multimedia-based content) and, in the broader sense, a knowledge system. 
Explorative learning gives the responsibility and the power to the users. They can learn whatever they want to learn, thereby increasing their motivation for learning [31]. However, due to the lack of a rigid learning path, explorative learning is more suitable for experienced users, who already have a basic knowledge and the ability to learn independently, whereas learning using traditional learning objects is more suitable for inexperienced users. One of the main problems of explorative learning is the lost-inhyperspace phenomena [32]. If the navigation and the status information are insufficient, the user gets lost in the hypertext system. This leads to frustration and a possible abortion of the learning session. Within the adaptation of a hypermedia system for a mobile learning application, only the presentation of the content has to be considered. Due the small screen size the same problems occur within the exposition.

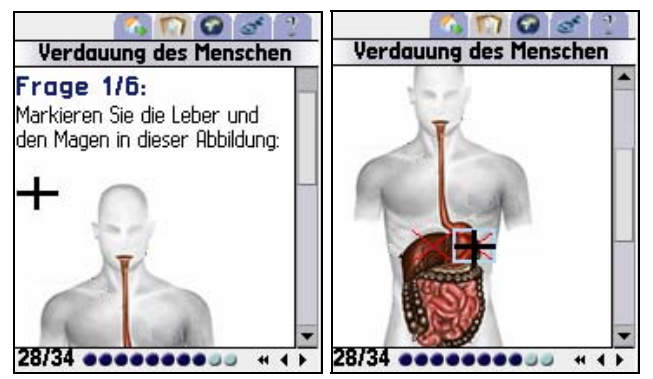

Figure 1: Example Screenshot of a MILO: Interactive questions

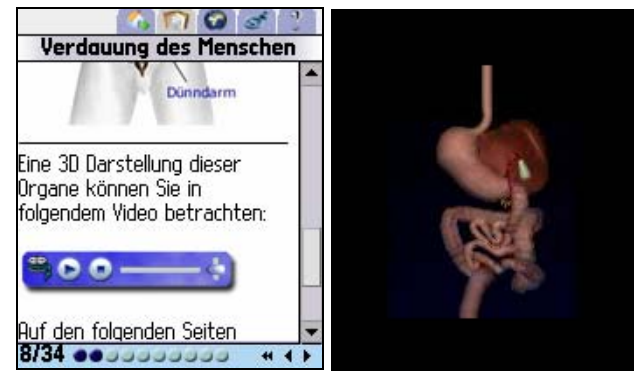

Figure 2: Example Screenshot of a MILO: Media-bar for the playback of a video

The learning objects for the MLE are written in XML (eXtensible Markup Language). XML is an open and international standard which is easy to learn. The use of XML makes it possible to present every kind of learning content. So the MLE is not restricted to those learning objects which are integrated in the application nor is it restricted to any particular kind of learning content. Within MILOs, the author can define interactive questions. The answer to these questions will be analyzed and corrected by the application itself. The author can also define hints for questions.

If the users' solution to a question is incorrect the application provides a hint, which should assist them to rethink the problem and help them to find the correct solution. Punishment in the form of a WRONG message is replaced by encouragement and assistance. By solving the question independently the users get a feeling of success and increase their knowledge.

\section{Conclusion and Future Work}

The Mobile Learning Engine (MLE) can be downloaded from http://www.mlearn.net free of charge. The feedback from end-users who have already used the MLE was very good. After a few minutes of use the majority of users could handle the MLE without any instructions. Most of the end-users were especially impressed by the features of the interactive questions and the multimedia-based content presented by the Mobile Interactive Learning Objects (MILOs).

However, m-Learning should not be used as a replacement for traditional e-Learning. It should be considered as a supplement to traditional e-Learning, where mobility is an added-value for the learners.

Mobile Learning makes sense, if it is used outside of a traditional e-Learning environment, where other means for the computer-aided learning are not available. The optimal system would be the integration of traditional teaching, e-Learning and $\mathrm{m}$-Learning. This enables students to learn in the classroom, at home with a desktop computer or, while underway in the field, on their mobile phones. Due to the fact that the MILOs are written in XML, it is also possible to present these learning objects on a desktop computer. Also the reuse of existing learning management systems for the MLE was considered during its development and aspects of further integration were also taken into consideration.

However, although mobile devices have a high availability, m-Learning is still in its infancy. To date little is known about the distinct attributes of mobile cooperative work in comparison to its stationary counterpart. We intend to carry out extensive research in this direction. 


\section{References}

[1] G. H. Forman and J. Zahorjan, "The Challenges of Mobile Computing," IEEE Computer, 27, 1994, pp. 38-47.

[2] C. Hermant, M. Alves, R. Apflauer, P. Baak, G. Barthel, I. Brandao, K. Ciba, J. De Craemer, G. E., A. Holzinger, P. Jethwa, J. Jokinen, F. Kelly, M. Lanners, G. Marucci, P. Matzakos, F. Nolan, L. Nydahl, D. Olesen, A. QuintanaAlonso, C. Regnier, U. Schampel, and A. Vogel, "Implementation of Education and Training 2010 Work Programme. White Paper of the WG "ICT in Education and Training", Brussels: European Commission, available online: http://europa.eu.int/comm/education/policies/2010/doc/ittechnologies en.pdf," 2003 (last access: 2004-11-19),

[3] A. Holzinger, "Usability Engineering und Prototyping, Beispiel Mobile Computing," OCG Journal (Forschung und Innovation), vol. 29, 2004, (in German) pp. 4-6.

[4] G. D. Abowd and E. D. Mynatt, "Charting Past, Present and Future Research in Ubiquitous Computing," $A C M$ Transactions on Computer-Human Interaction (TOCHI). Special Issue on HCI in the new Millenium, 2000, pp. 29-58.

[5] A. Holzinger, Basiswissen IT/Informatik, Band 1: Informationstechnik (IT). Würzburg: Vogel, (in German) 2004. http://www.basiswissen-it.at

[6] E. Ammenwerth, A. Buchauer, B. Bludau, and R. Haux, "Mobile information and communication tools in the hospital," International Journal of Medical Informatics, vol. 57, 2000, pp. 21-40

[7] K. Hameed, "The application of mobile computing and technology to health care services," Telematics and Informatics, vol. 20, 2003, pp. 99-106.

[8] A. Holzinger, "Mobile Computing in der Medizin: Möglichkeiten und Perspektiven. In, 8/2004, Wien: Manstein Medizin," CliniCum, 2004, pp. 28-29.

[9] E. Reuss, M. Menozzi, M. Buchi, J. Koller, and H. Krueger, "Information access at the point of care: what can we learn for designing a mobile CPR system?" International Journal of Medical Informatics, vol. 73, 2004, pp. 363-369.

[10] J. S. Lombardo, M. McCarty, and R. A. Wojcik, "An evaluation of mobile computing for information access at the point of care," Biomedical Instrumentation \& Technology Association, 31, 1997, pp. 465-475.

[11] H. Maurer, "Web-Based Knowledge Management," IEEE Computer, vol. 31, 1998, pp. 122-123.

[12] M. Sharples, "The design of personal mobile technologies for lifelong learning," Computers \& Education, vol. 34, 2000, pp. 177-193.

[13] WKO, "The Telecommunication Market in Austria and International (in German)," 2004.

[14] E. C. Tolman, Purposive Behavior in Animals and Men. New York: Appleton-Century-Crofts, 1932.
[15] A. Newell and H. A. Simon, Human Problem Solving. Englewood Cliffs (NJ): Prentice-Hall, 1972.

[16] S. Kim, B. E. Kolko, and T. H. Greer, "Web-based problem solving learning: third-year medical students' participation in end-of-life care Virtual Clinic," Computers in Human Behavior, vol. 18, 2002, pp. 761-772.

[17] H. S. Barrows and R. M. Tamblyn, "An evaluation of problem-based learning in small groups utilizing a simulated patient," Journal of Medical Education, 51, 1976, pp. 52-54.

[18] J. S. Bruner, "The Act of Discovery," Harvard Educational Review, vol. 31, 1961, pp. 21-32.

[19] R. Schank and A. Kass, "A goal-based scenario for high school students," Communications of the ACM, vol. 39, 1996 , pp. 28-29.

[20] S. Guttormsen-Schär and H. Krueger, "Using New Learning Technologies with Multimedia," IEEE MultiMedia, vol. 7, 2000, pp. 40-51.

[21] S. Papert and I. Harel, Constructionism. Norwood (NJ): Ablex Publishing, 1991

[22] J. Brown, A. Collins, and P. Duguid, "Situated cognition and the culture of learning," Educational Researcher, vol. 18,1989 , pp. 32-42.

[23] S. Billett, "Situated learning: bridging sociocultural and cognitive theorising," Learning and Instruction, vol. 6, 1996, pp. 263-280.

[24] J. A. Muzio, T. Heins, and R. Mundell, "Experiences with reusable E-learning objects; From theory to practice," The Internet and Higher Education, vol. 5, 2002, pp. 21-34.

[25] V. Venkatesh, V. Ramesh, and A. P. Massey, "Understanding usability in mobile commerce," Communications of the ACM, vol. 46, 2003, pp. 53-56.

[26] G. A. Miller, "The magical number seven, plus or minus two: Some limits of our capacity for processing information," Psychological Review, vol. 63, 1956, pp. 81-97.

[27] H. A. Simon, "How big is a chunk?" Science, vol. 183, 1974, pp. 482-488.

[28] H. R. Hartson and D. Hix, "Human-computer interface development: concepts and systems for its management," ACM Computing Surveys (CSUR), vol. 21, 1989, pp. 5-92.

[29] R. M. Gagne, The Conditions of Learning. New York: Holt, Rinehart and Winston, 1965.

[30] S. de Mul and H. van Oostendorp, "Learning user interfaces by exploration," Acta Psychologica, vol. 91, 1996, pp. $325-344$

[31] A. Holzinger, "Computer-aided Mathematics Instruction with Mathematica 3.0," Mathematica in Education and Research, vol. 6, 1997, pp. 37-40.

[32] R. A. Botafogo, E. Rivlin, and B. Shneiderman, "Structural analysis of hypertexts: identifying hierarchies and useful metrics," ACM TOIS, 10, 1992, pp. 142-180. 